\title{
The biotechnologist's jungle book
}

\section{A look at the pharmaceutical treasure trove of the Amazonian rainforest.}

\section{Medicine Quest: In Search of Nature's Healing Secrets by Mark J. Plotkin \\ Viking: 2000. 304 pp. $\$ 22.95$ \\ Walter Gratzer}

"If you are fat, fleshy, brightly coloured and slow moving, I want to see you," says Dr David Newman of the National Cancer Institute, and he is not alluding here to the matriarchs of our affluent society. "There's something in you, on you, or travelling with you," he continues, "that stops you from being eaten." Or, as Mark Plotkin puts it in this sprightly, engrossing and often startling account of nature's bounteous therapeutic gifts to man, "the creature with the best chemistry set wins". So, indeed, do ailing humans and, of course, the pharmaceutical companies, whose chemists toil at isolating the channel and receptor blockers, vasodilators, anticoagulants, antibiotics and anaesthetics that these animals and plants so copiously harbour. For, as Plotkin reveals, the US retail take from anticoagulants and thrombolytic agents alone passed $\$ 700$ million in 1993 and is rising fast. Morphine and its relatives gross $\$ 600$ million per annum, and Plotkin estimates the national cost of pain, measured by drugs, doctors' bills and lost income, at about $\$ 100$ billion.

Medicine Quest, then, is no mere collection of arcana of natural history. Some $70 \%$ of pharmaceuticals now in use are or derive from natural products. (Most of the rest probably sprang from fortuitous discoveries: physiological effects sometimes came to light when organic chemists cautiously tasted their reaction product. And the anticancer drug cisplatin, for instance, resulted from an attempt to assess whether an electric current could affect the growth of bacteria: the misshapen forms that appeared in an Escherichia coli suspension resulted, it eventually turned out, from the activity of a reaction product of chloride ions with the platinum electrode.)

Plotkin observes that the majority of the species to which our planet is host live in the seas, and their biology remains largely unexplored. Carnivorous marine snails alone have produced a myriad of physiologically active substances, and it was a sponge that yielded the adenine nucleoside of which AZT is a synthetic derivative. Small wonder, then, even if only one in 10,000 therapeutically promising substances makes it to the market-place, that a shoal of small companies with names such as Cal Bio Marine, Pharma Mar and Oceanix Biosciences have taken to the water.
But Plotkin's real passion is for the Amazonian rainforest and its denizens. Here is the arrow-poison frog; this secretes vasodilators and analgesics, as well as a cardiac-channel blocker that acts on a different calcium pump from that inhibited by digitalis. Then there is the leech, which injects an anticoagulant, a vasodilator and an anaesthetic to render its victim unaware of a six-inch proboscis lustily probing its flesh. The giant, 18-inch leech of nightmares is armed not only with anticoagulants but also with a clotdissolving enzyme. A vast range of anticoagulants, acting at different levels in the clotting cascade, is to be found in ticks and vampire bats (draculin), and a component of viper venom, which reduces platelet adhesion, is being tested as a treatment for angina. There is the monster toad, which exudes hallucinogens (and was introduced into Australia, where it has established itself as a pest and apparently serves as a lollipop for the local junkies in search of a cheap fix).

Plotkin conjectures that autochthonous tribes learned about the medicinal properties of the indigenous flora by observing the behaviour of animals. A monkey with diarrhoea will peel and chew the bitter bark of the Vernonia bush, which African tribespeople use to treat the same condition; pigs use pomegranate roots, which contain a vermifuge, to treat (apparently) parasitic infestations; tapirs eat the nekoe plant, the toxins of which pass through the intestines; the sagacious animals then, Plotkin assures us, hasten to the nearest river where they deposit their droppings to narcotize the fish on which they like to feast.

Plotkin is plainly entranced by the rainforest, and likes to consort with shamans, who feature prominently in his earlier book, Tales of a Shaman's Apprentice (Penguin, 1994). He often shares the life of the forest tribesmen and is not above displaying the occasional flash of bravado ("I grabbed my machete and followed him ... together we entered the twilight-green world of the forest"). He appears at times a little too persuaded of the shamans' powers, and some of his anecdotes of seemingly miraculous cures will stretch the credulity of sceptical readers.

But these are small cavils about what I believe is an important book. Plotkin seeks not only to entertain and inform (in which he abundantly succeeds), but also to warn, especially against some of the consequences of man's destruction and pollution of the world. Francis Bacon declared that nature, to be commanded, must be obeyed. His injunction, as we all know, has not been

\section{Healing hues}

Foxgloves are the source of digitalis, a substance with powerful effects on the heart, used to treat congestive heart failure and cardiac arrhythmias. Nature's Medicine: Plants That Heal by Joel L. Swerdlow with photographs by Lynn Johnson (National Geographic, $\$ 35, £ 20$ ), from which this picture is taken, traces man's search for healing plants through the ages, from the ancient civilizations of China and India through to the birth of modern pharmaceutical science.

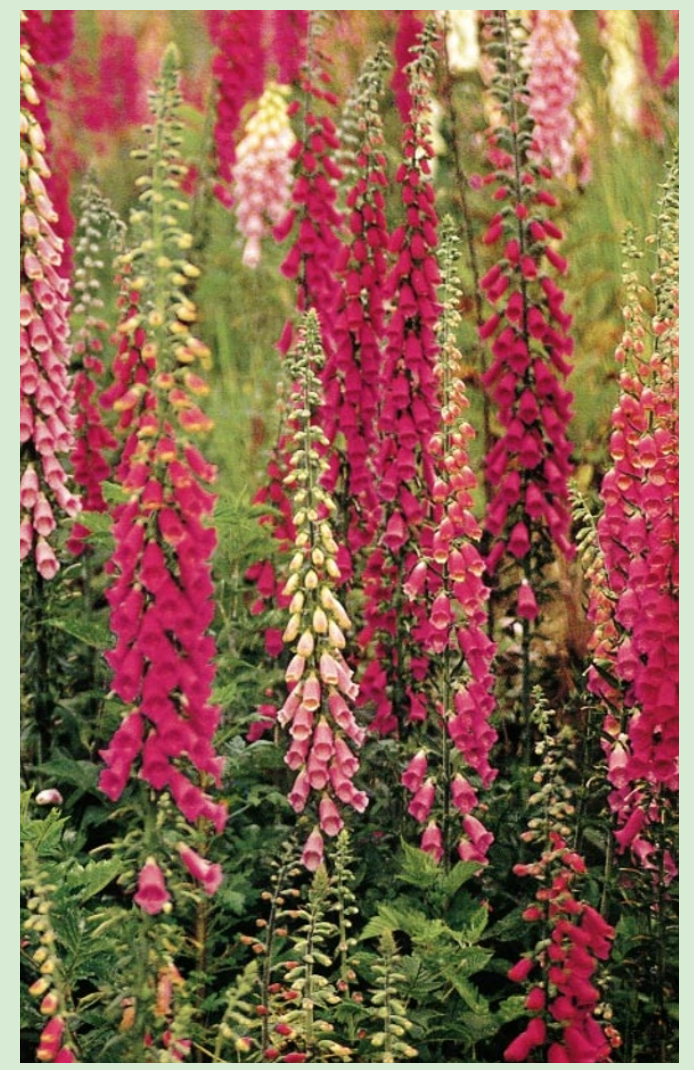


observed. There are many other reasons why what little remains of the tropical forests should be cherished, but what Plotkin laments here is that the annihilation of species by the thousand deprives us of untold opportunities to discover new medicines and other valuable classes of compounds strong materials, process chemicals and many more.

He also denounces the profligacy with which existing therapeutic resources are being degraded: antibiotics are still fed to cattle and federal law is content to allow trace amounts of no fewer than 80 antibiotics to enter the milk that Americans drink. And finally, Plotkin notes, a large proportion of the most important medicinal substances were brought to us by research driven only by curiosity about the natural world and mocked by Senator William Proxmire and his allies as a waste of the taxpayers' money. Let us hope that Plotkin's voice is heard in the quarters that count, those in which economic and not moral interests prevail. Dr Johnson put it pithily: "Sir, I have found you an argument, but I am not obliged to find you an understanding."

Walter Gratzer is at the Randall Centre for

Molecular Mechanisms of Cell Function,

New Hunt's House, Guy's Campus,

St Thomas Street, London SE1 1UL, UK.

\section{A function for dysfunction}

Ion Channels and Disease

by Frances M. Ashcroft

Academic: 1999.352 pp. $£ 46.95, \$ 75$

Thomas J. Jentsch

The importance of many things in our lives becomes apparent only when we lose them, or when they malfunction. In genetic disease, mutations in a gene may lead to interesting and sometimes unexpected insights into the physiological importance of their product. Detailed comparison of the properties of both the normal and mutant gene products can reveal deep insights into the physiological role of the protein encoded by the gene and how it goes awry in disease.

This combination frequently occurs in ion-channel diseases (or 'channelopathies'). Over the past 15 years, genes encoding ion channels have been isolated at ever-increasing rates. Their number exceeds estimates obtained from biophysical studies, and one might wonder why there are so many different channels. In many cases, mutations in ion-channel genes, in both humans and animals, have provided clues or answers. Some ion-channel genes were even cloned on the basis of the effects of their disruption. For example, positional cloning in the fruitfly

\section{Channelling other energies}

The Kongo peoples inhabit the River Congo region in west-central Africa, and are divided into many subgroups, all of which have many different cults. Their strong belief in a wide spectrum of spiritual forces catalysed the development of a wealth of sculptural forms dedicated to containing and harnessing these forces. The statue shown here, called $n k i s i$ nkonde, represents a power figure generally associated with vengeance and aggression, but it could also be involved in the sealing of pacts between individuals - each nail or point driven into the statue reinforces the pact. Failure to keep the pact would provoke retribution from nkisi nkonde's particularly ferocious spirit. From Spirits Embodied: Art of the Congo by Evan M. Maurer and Niangi Batulukisi (University of Minnesota Press, $\$ 34.95$, 24.50 ).

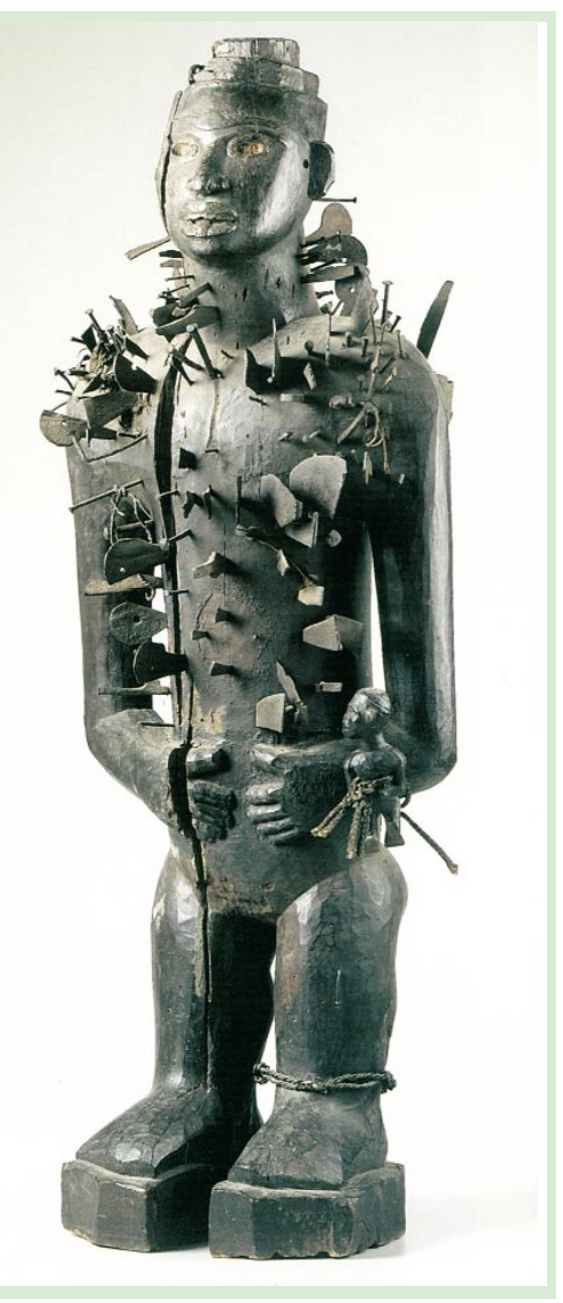

Drosophila led to the isolation of the shaker potassium channel, and the CFTR chloride channel was found because its gene is mutated in cystic fibrosis.

The large number of ion-channel diseases provides an impressive illustration of the many functions of channels. These range from signal transduction to ionic homeostasis, cell-volume regulation, transepithelial transport, vesicle acidification and trafficking, and cytotoxic effects, to name just a few. As a result, ion-channel diseases are clinically very diverse, ranging from cystic fibrosis to inherited forms of kidney stones, periodic paralysis, high blood pressure, epilepsy and hyperinsulinaemia.

Ion channels can be studied in great detail using biophysical methods. One such method is the patch-clamp technique, which investigates the properties of single molecules in real time. The in vitro analysis of channel mutations found in patients has contributed considerably to our understanding of the relationships between channel structure and function. Compared with most other genetic diseases, this provides an unrivalled level of understanding of how mutations cause disease.

Frances Ashcroft's book is a fascinating and accessible account of ion-channel diseases. But it does not stop there - it is also an up-to-date description of the different classes of cloned ion channels, their structure and function, and how the disease characteristics resulting from their dysfunction are used to elucidate their physiological roles. For completeness, channels not (yet) known to cause human disease are also covered, and the chapter "Ion channels as lethal agents" even discusses the pore-forming peptides of bacteria and fungi.

Ashcroft begins with a short introduction on the essentials of molecular biology, human genetics, electrophysiology and ionchannel design. Although necessarily superficial, this section will be useful for students from different backgrounds. Beginning with voltage-dependent sodium channels, the author goes on to discuss the different classes of ion channels individually. Only cloned ion channels are included, thereby omitting several classes of ion channels (such as calcium-activated chloride channels) whose molecular correlate has not been firmly established.

These chapters begin with a concise description of what is known about the structure and function of the channels, and a discussion of the key experiments that led to these insights. The physiological role of the 